\begin{tabular}{|c|l|}
\hline Title & Biot' sEffective Stress Coefficient of Rocks for Peak and Residual Strengths by Modified Failure Envelope Method \\
\hline Author(s) & Dassanay ake, A njula Buddhika Nay omi; Fujii, Y oshiaki \\
\hline Citation & Rock Engineering and Rock Mechanics: Structures in and on Rock Masses, ISBN: 978-1-13800-149-7, 155-160 \\
\hline Issue Date & 201405 \\
\hline Doc URL & http:/hdl.handle.net/2115/58548 \\
\hline Type & proceedings (author version) \\
\hline Note & 2014 ISRM European Rock Mechanics Symposium (EUROCK 2014), May 27-29, 2014, Vigo, Spain. \\
\hline File Information & EUROCK 2014.155-160.pdf \\
\hline
\end{tabular}

Instructions for use 


\title{
Biot's effective stress coefficient of rocks for peak and residual strengths by modified failure envelope method
}

\author{
A.B.N. Dassanayake \& Y. Fujii \\ Hokkaido University, Sapporo, Hokkaido, Japan
}

\begin{abstract}
Kimachi sandstone and Shikotsu welded tuff were tested in single and multistage triaxial tests to determine the Biot's effective stress coefficient $(\alpha)$. Pure water saturated $30 \mathrm{~mm}$ in diameter and length of $60 \mathrm{~mm}$ cylindrical test specimens were introduced for triaxial compression, with strain rate at $10^{-5} \mathrm{~s}^{-1}$. For Kimachi sandstone, $\alpha$ value for peak strength decreased with effective confining pressure. $\alpha$ values for residual strength were almost constant and larger than the case of peak strength. For Shikotsu welded tuff, only two data points were obtained for peak strength due to pore collapse and $\alpha$ value for residual strength decreased with effective confining pressure. The multistage test has given a fair evaluation of the coefficient for peak strength of Kimachi snadstone. Number of specimens and variation from specimen to specimen can be reduced by using multistage tests although further considerations are required to obtain the coefficient for residual strength.
\end{abstract}

\section{INTRODUCTION}

Experimental determination of Biot's effective stress coefficient, $\alpha$ for peak and residual strengths is very important in rock engineering problems because failure criteria for strengths of rocks are written by effective stress.

The concept of effective stress was first introduced by Terzaghi (Terzaghi, 1936) for soil, which is commonly known as the Terzagi's effective stress principle. It states that the effect of the total stress $\sigma$ and pore pressure $P_{\mathrm{p}}$ can be denoted by a single parameter which is known as effective stress $\sigma^{\prime}$ defined as,

$$
\sigma^{\prime}=\sigma-P_{\mathrm{p}}
$$

Terzarghi's effective stress principle is not always valid for the fluid related rocks. Therefore, the Biot's effective stress coefficient was suggested by Biot and Willis in 1957 to modify the effective stress principle and the effective stress principle finally is given by,

$\sigma^{\prime}=\sigma-\alpha P_{\mathrm{p}}$

where $\alpha$ is the Biot's effective stress coefficient which denotes the ratio of the area occupied by the fluid to the total area in a cross section in the porous material (Bear, 1972) and is the key parameter that quantifies the contribution of pore pressure to the effective stress. For the granular soil, the contact area among grains is very small, thus it is possible to assume that a cross section which is considered is almost occupied by the fluid. Hence, the corresponding effective stress coefficient $\alpha$ approximately equals to 1 . In rock materials composed of crystallization or cementation, grain to grain contact is considerably higher and it is not possible to assume that the cross section is almost occupied by the fluid. Consequently the corresponding effective stress coefficient $\alpha$ will be less than 1 .

The Biot's effective stress coefficient, $\alpha$, is usually calculated from experimental results within the elastic region based on the poroelasticity theory. Values for peak and residual strengths are important when using it to evaluate rock failure, but $\alpha$ obtained as above does not have to be valid for the strengths because rocks exhibit an inelastic behavior. Failure envelope method proposed by Franquet \& Abass (1999) evaluates $\alpha$ based on peak strength. This method needs a large number of specimens. They however showed just two data for a rock, and a tedious and not precise trial and error method was used for the evaluation. The authors propose a Modified Failure Envelope Method (MFEM) and use it to evaluate $\alpha$ for peak and residual strengths of Shikotsu welded tuff and Kimachi sandstone.

MFEM also needs rather many specimens. Multistage test is examined to reduce the number of specimens as well as the error caused by differences of mechanical properties from specimen to specimen.

\section{METHODOLOGY}

\subsection{Modified failure envelope method}

Strength of rock can be analyzed in an effective confining pressure-differential stress plane by correlating strength parameters measured at different boundary conditions (Fjaer et al., 2008). MFEM incorporates this concept to evaluate Biot's effective stress coefficient. MFEM requires constructing a failure envelope 


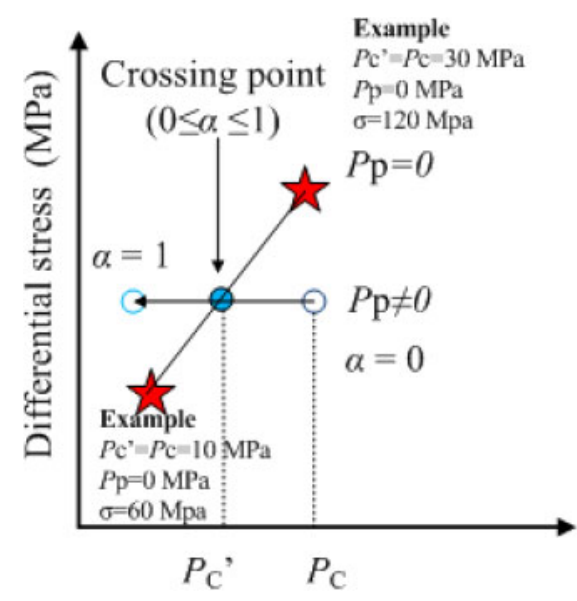

Figure 1. Evaluation of $\alpha$ by the modified failure envelope method.

on the plane for saturated samples tested in triaxial cell without pore pressure first, and then for saturated samples with specific pore pressures.

From the first set of tests (without pore pressure):

Effective confining pressure $=$ total confining pressure

$P_{\mathrm{c}}^{\prime}=f\left(P_{\mathrm{c}}, P_{\mathrm{p}}\right)=P_{\mathrm{c}}$

From the second set of tests (with varying confining and pore pressure):

$P_{\mathrm{c}}^{\prime}=f\left(P_{\mathrm{c}}, P_{\mathrm{p}}\right)=P_{\mathrm{c}}-\alpha P_{\mathrm{p}}$

Peak differential stress data can be plotted on the differential stress-confining pressure plane assuming that $\alpha=0$. Data with pore pressure can be moved to the left by increasing $\alpha$ from 0 to 1 (Fig. 1). The crossing point can be easily calculated and the $\alpha$ value can be obtained from the effective confining pressure $P_{\mathrm{C}}^{\prime}$ at that point as,

$\alpha=\frac{P_{\mathrm{C}}-P_{\mathrm{C}}^{\prime}}{P_{\mathrm{p}}}$

\subsection{Laboratory tests}

\subsubsection{Specimen and Sample Preparation}

Two types of rock blocks were considered in this research namely Shikotsu welded tuff, as an example of a soft pyroclastic rock and Kimachi sandstone as a medium-hard clastic rock. The Shikotsu welded tuff was sampled at Hokkaido, Japan. It presents distinct welded structure which consisted of plagioclase, hypersthene, augite, hornblende, and transparent glass. The grain sizes of the minerals were $0.51 .2 \mathrm{~mm}$ for plagioclase, about $0.5 \mathrm{~mm}$ in size for augite, $0.30 .8 \mathrm{~mm}$ for hypersthene and $0.31 .0 \mathrm{~mm}$ for hornblende (Doi, 1963). The Kimachi sandstone was sampled at Shimane prefecture, Japan, and was a relatively well-sorted clastic rock with a typical grain size
Table 1. Target values of confining and pore pressures.

\begin{tabular}{lllllll}
\hline Confining pressure (MPa) & \multicolumn{6}{l}{ Pore pressure (MPa) } \\
\hline 2 & 0 & 1 & & & \\
5 & 0 & 1 & 4 & & \\
10 & 0 & 1 & 4 & 9 & \\
15 & 0 & 1 & 4 & 9 & 14
\end{tabular}

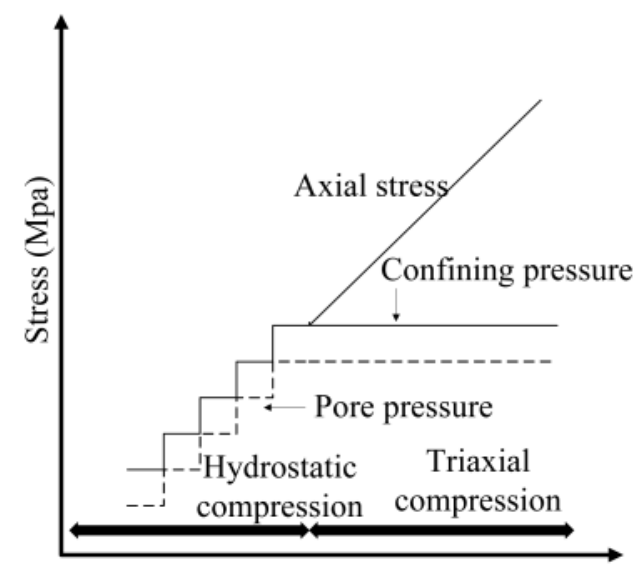

Time

Figure 2. Procedure to reach the target confining pressure, pore pressure and compression phase of triaxial test.

range of $0.41 .0 \mathrm{~mm}$. It consisted mostly of rock fragments of andesite; crystal fragments of plagioclase, pyroxene, hornblende, biotite, and quartz; calcium carbonate and iron oxides; and matrix zeolites (Dhakal et al., 2002).

Firstly, the P-wave velocities of the rock blocks were measured with $140 \mathrm{kHz}$ sensors to determine the anisotropy. Core boring was carried out in the direction of the slowest P-wave velocity to a diameter of $30 \mathrm{~mm}$ and cut to a length of $65 \mathrm{~mm}$. End faces of specimens were ground to the length of $60 \mathrm{~mm}$ with a parallelism of $2 / 100$.

The specimens were made fully pure water saturated under a vacuum condition. Then the samples were attached to stainless steel endpieces, having a central hole for water seepage, and silicone sealant was coated on the specimen. The specimen with the endpieces was jacketed with heat shrinkable tube and thus isolated from confining water and it was saturated with pure water for 24 hours.

\subsubsection{Single stage triaxial tests}

The jacketed sample was set in the ultra compact triaxial cell (Alam, 2014) after it was saturated with pure water for 24 hours. After completing the experimental set up (Fig. 3), axial stress, confining pressure and pore pressures were introduced successively up to the target values as in Table 1 (Fig. 2).

Axial compression was introduced at a constant axial strain rate of $10^{-5} \mathrm{~s}^{-1}(0.036 \mathrm{~mm} / \mathrm{min})$ until the axial strain reached to $5 \%$. 


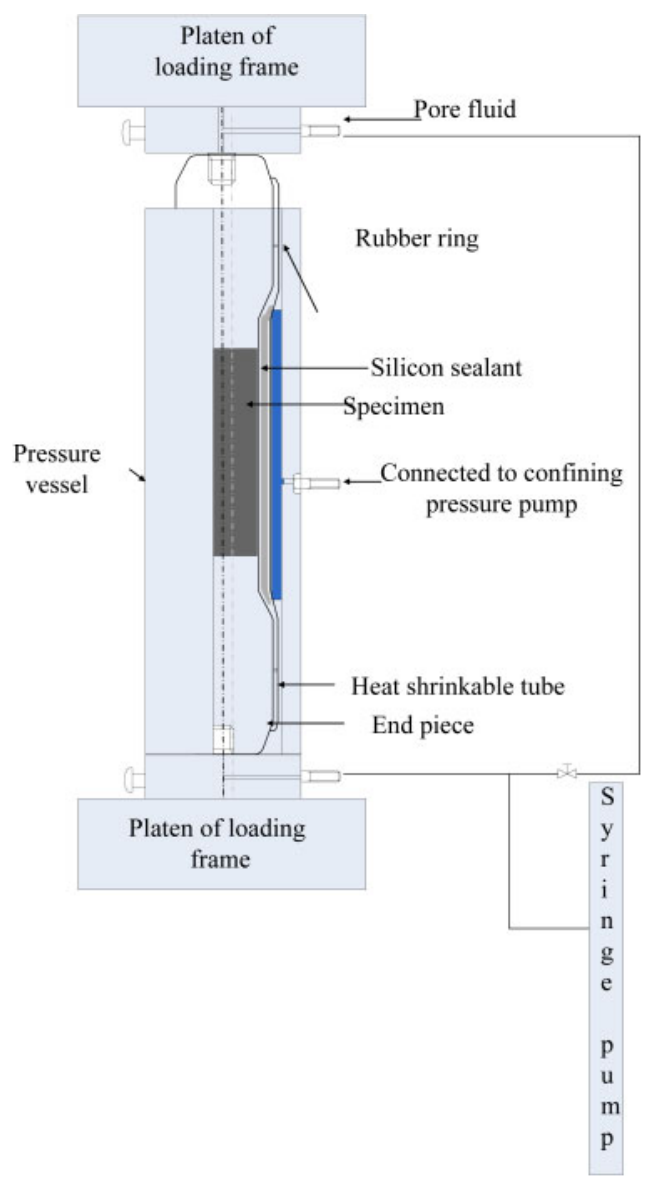

Figure 3. Experimental setup with ultra compact triaxial cell.

\subsubsection{Multistage triaxial tests}

In conventional single-stage triaxial test, a large number of specimens are required to obtain the complete strength envelope in which a confining pressure is set and the axial load is applied until the specimen fails as explained above. But in multi-stage triaxial test, test conditions are changed to the next level just before the peak loading point; imminent failure point and consequently one multi-stage triaxial test may give the complete failure envelope.

In multi-stage triaxial test, only two samples per each rock type were required. One sample was tested without applying pore pressure. The confining pressure was increased stepwise to $2 \mathrm{MPa}, 5 \mathrm{MPa}, 10 \mathrm{MPa}$ and $15 \mathrm{MPa}$. After confining pressure was introduced successively up to the 1 st target value ( $2 \mathrm{MPa}$ ), axial compression was introduced at a constant axial strain rate of $10^{-5} \mathrm{~s}^{-1}(0.036 \mathrm{~mm} / \mathrm{min})$ till it reach for the first imminent failure point. After the first imminent failure point, the differential stress is released completely (Youn \& Tonon 2010) and the confining pressure was hydrostatically increased to the next level (Fig. 4), after which the differential stress was

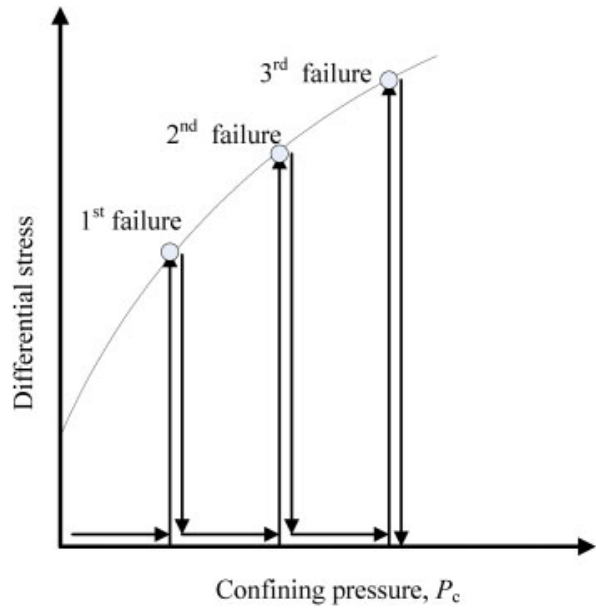

Figure 4. Stress paths of multi-stage triaxial test - with zero pore pressure.

Table 2. Target values of confining and pore pressures for multistage test with pore pressure.

\begin{tabular}{lc}
\hline Confining pressure (MPa) & Pore pressure (MPa) \\
\hline 15 & 14 \\
15 & 12 \\
15 & 10 \\
15 & 8 \\
15 & 5 \\
15 & 1 \\
\end{tabular}

increased to the second imminent failure point, and so on. The imminent failure point was defined by the region of the stress-axial strain curve where the tangent modulus approaches zero. The second sample was tested by applying pore pressure. In this test, confining pressure and pore pressure were introduced successively up to the 1 st target value (15 MPa and $14 \mathrm{MPa}$ ) and then, axial compression was introduced at the same strain rate till it reach for the 1 st imminent failure point. After the first imminent failure point, pore pressure was reduced to the next level while maintaining a constant confining pressure of $15 \mathrm{MPa}$ and introduced the axial stress to the second imminent failure point. This procedure was repeated for 6 steps as illustrated in Table 2. Before plotting the peak differential stresses for second sample $\left(P D S_{2}\right)$, the stresses were corrected as,

$P D S_{2}^{\prime}=\frac{P D S_{1}^{0}}{P D S_{2}^{0}} \cdot P D S_{2}$

where $P D S_{i}^{0}$ denotes peak differential stress of $i$-th specimen under zero pore pressure. 


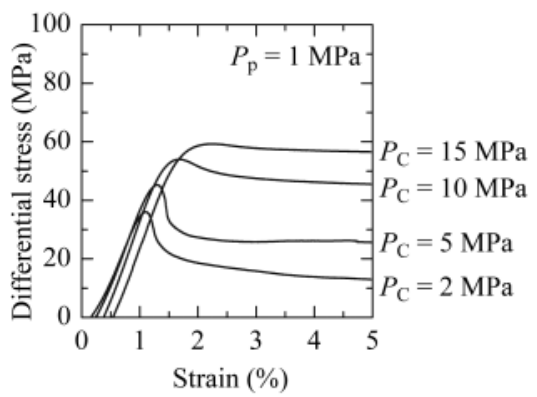

(a)

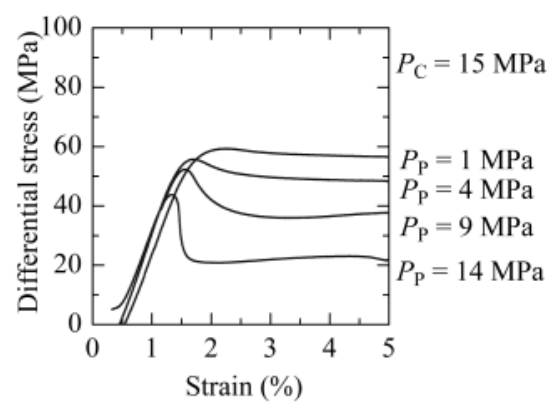

(b)

Figure 5. Differential stress versus stoke based strain for different confining pressures and pore pressures for Kimachi sandstone. a) Effect of confining pressure b) Effect of pore pressure.

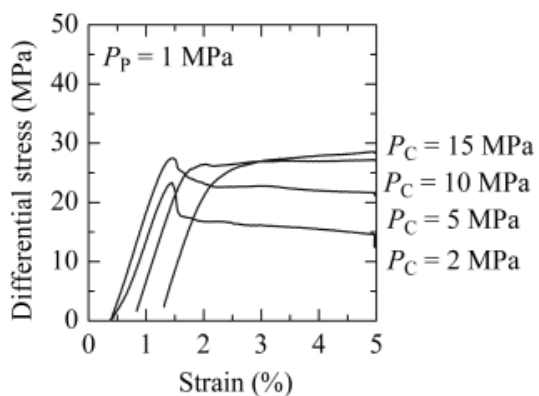

(a)

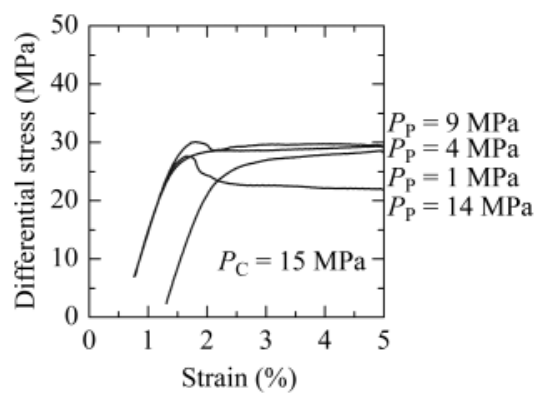

(b)

Figure 6. Differential stress versus stoke based strain for different confining pressures and pore pressures for Shikotsu welded tuff. a) Effect of confining pressure. b) Effect of pore pressure.

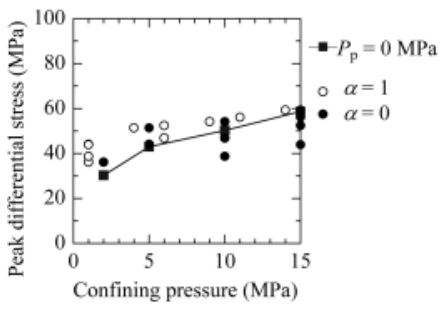

(a)

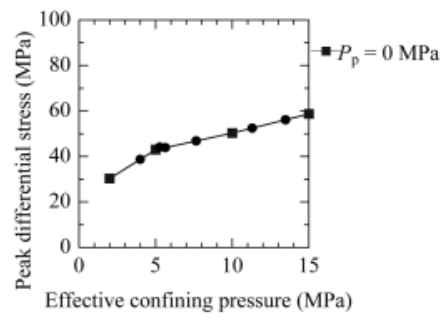

(b)

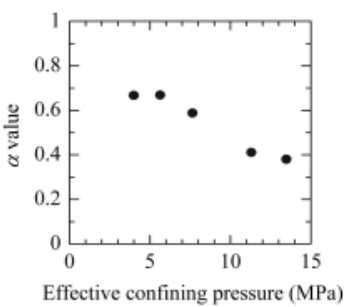

(c)

Figure 7. Peak strength results of Kimachi sandstone by single stage triaxial tests. a) PDS (Peak Differential Stress) vs ECP (Effective Confining Pressure) when $\alpha=0$ and $\alpha=1$. b) DS vs ECP for exact $\alpha$ obtained by MFEM. c) $\alpha$ value variation with ECP.

\section{RESULTS AND DISCUSSION}

In the single stage tests, 14 samples were tested for each rock type with and without pore pressure as in Table 1 (Figs. 5 and 6). In Kimachi sandstone, an increase in peak strength (Fig. 7a), residual strength (Fig. 8a), and a transition from typical brittle to ductile behavior (Fig 5a) with increasing confining pressure were clearly observed. The inverse happens when introducing pore pressure. There is a transition from ductile to brittle behavior as pore pressure is increased (Fig 5b).
In Shikotsu welded tuff (Fig. 6), the peak strength increased initially, but at higher confining pressures, it decreased (Figs. 10a and 12) to get an end cap like curve that close the failure surface at high stresses. Reason for this behavior is pore collapse (Zaman et al., 1994) due to crushing of rock matrix consisting of volcanic glass.

Peak differential stresses and residual differential stresses obtained from the results with pore pressure in the single stage tests are shown in Figs. 7a, 8a, $10 \mathrm{a}$ and $11 \mathrm{a}$ assuming the Biot's effective stress coefficient as 0 and 1 . The coefficient can be obtained 


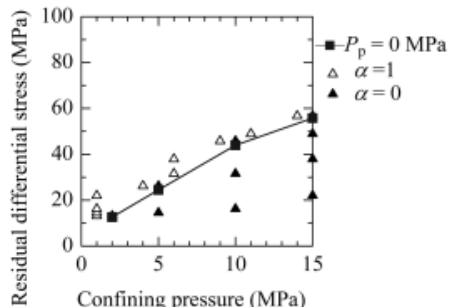

(a)

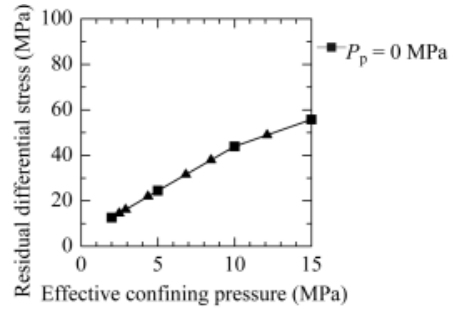

(b)

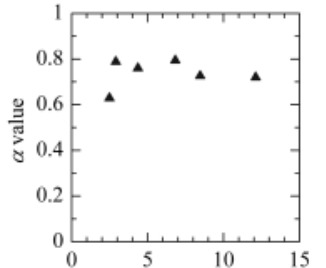

Effective confining pressure (MPa)

(c)

Figure 8. Residual strength results of Kimachi sandstone by multi stage triaxial tests. a) RDS vs ECP when $\alpha=0$ and $\alpha=1$. b) RDS vs ECP for exact $\alpha$ obtained by MFEM. c) $\alpha$ value variation with ECP.

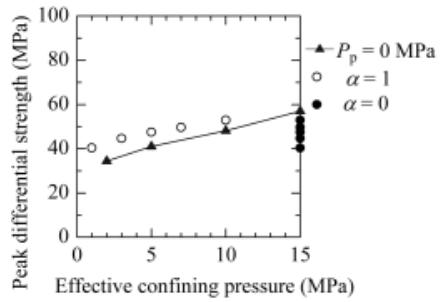

(a)

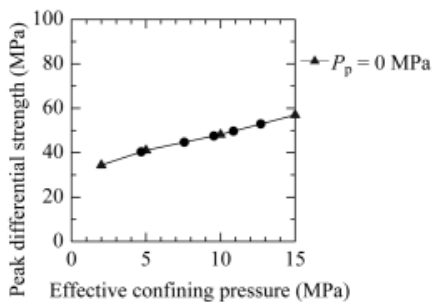

(b)

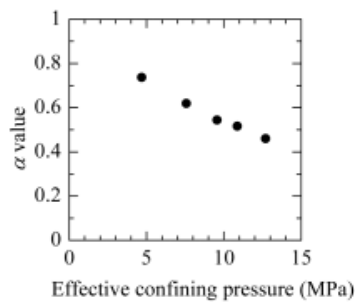

(c)

Figure 9. Peak strength results of Kimachi sandstone by multi stage triaxial tests. a) PDS vs ECP when $\alpha=0$ and $\alpha=1$. b) PDS vs ECP for exact $\alpha$ obtained by MFEM. c) $\alpha$ value variation with ECP.

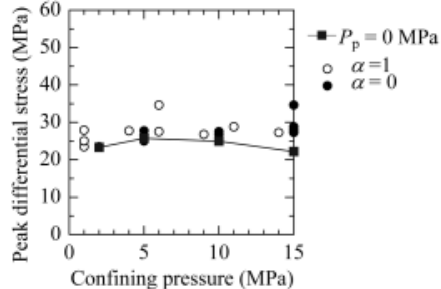

(a)

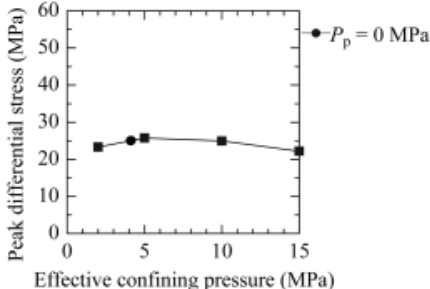

(b)

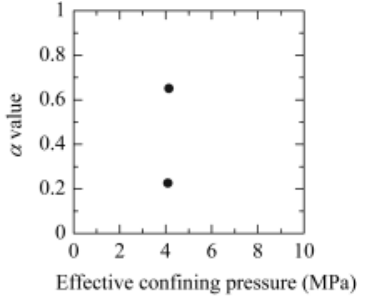

(c)

Figure 10. Peak strength results of Shikotsu welded tuff by single stage triaxial tests. a) PDS vs ECP when $\alpha=0$ and $\alpha=1$. b) PDS vs ECP for exact $\alpha$ obtained by MFEM. c) $\alpha$ value variation with ECP.

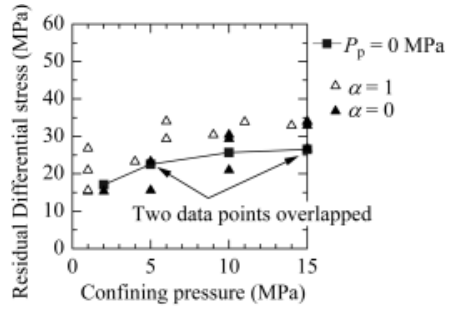

(a)

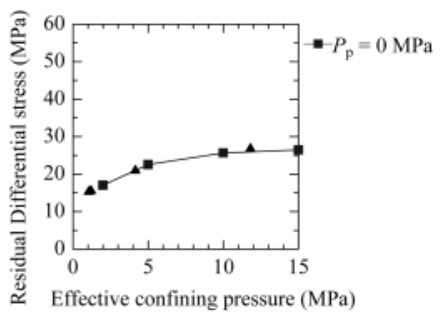

(b)

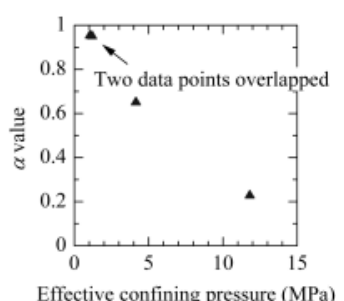

(c)

Figure 11. Residual strength results of Shikotsu welded tuff by single stage triaxial tests. a) RDS vs ECP when $\alpha=0$ and $\alpha=1$. b) RDS vs. ECP for exact $\alpha$ obtained by MFEM. c) $\alpha$ value variation with ECP.

if the stresses can be moved on the failure envelope for the results without pore pressure by adjusting the coefficient (Figs. 7b, 8b, 10b and 11b).

The coefficient for the peak strength for Kimachi sandstone decreased with effective confining pressure (Fig. 7c). For residual strength, the coefficient was larger than that for the peak strength and showed almost a constant value (Fig. 8c).

It was difficult for the peak strength of Shikotsu tuff to move the data on the failure envelope and two values of the coefficient were hardly obtained (Fig. $10 \mathrm{c})$ because strength values with pore pressures were 


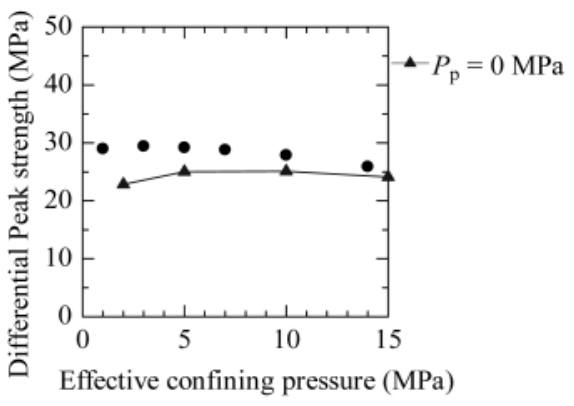

Figure 12. Peak strength results of Shikotsu welded tuff by multi stage triaxial tests; PDS vs ECP when $\alpha=1$.

larger than those with zero pore pressure in many cases, due to pore collapse. It was slightly easier to obtain the coefficient value for the residual strength. The coefficient was calculated for 4 data points and it decreases with the effective confining pressure (Fig. 11c). The decrease of $\alpha$ value for residual strength with effective confining pressure shows the progress of pore collapse. Poroelasticity itself cannot be applied to this condition.

Figures 9 and 12 illustrate the results of multi stage triaxial tests. For Kimachi sandstone, peak strength values are almost the same as those by single stage tests, mainly no significant effects of loading history were observed (Fig. 9a). The coefficient values were also almost the same as those from the single stage tests (Fig. 9c). The variation in either peak strength or $\alpha$ is much smaller than that in the single stage tests and this is one of the advantages of the multi stage tests.

For Shikitsu welded tuff, the peak strength with pore pressures was larger than that without pore pressure and the coefficient was not obtained (Fig. 12).

The coefficient for residual strength was not obtained by multistage tests even for Kimachi sandstone since larger strains were required for the both rocks to stabilize axial stress value than the capacity of the apparatus.

\section{CONCLUSION}

Kimachi sandstone and Shikotsu welded tuff were tested in single and multistage triaxial tests to determine the Biot's effective stress coefficient. Pure water saturated $30 \mathrm{~mm}$ in diameter and length of $60 \mathrm{~mm}$ cylindrical test specimens were introduced for triaxial compression, with strain rate at $10^{-5} \mathrm{~s}^{-1}$.

For Kimachi sandstone, $\alpha$ value for peak strength decreased with effective confining pressure. $\alpha$ values for residual strength were almost constant and larger than the case of peak strength. For Shikotsu welded tuff, only two data points were obtained for peak strength because of pore collapse. $\alpha$ value for residual strength decreased with effective confining pressure.

The above results imply that MFEM can be used to evaluate the Biot's effective stress coefficient for both peak and residual strengths at least for medium hard clastic rocks.

The multistage test has given a fair evaluation of the coefficient for peak strength of Kimachi sandstone Number of specimens and variation from specimen to specimen can be reduced by using multistage tests although further considerations are required to obtain the coefficient for residual strength.

MFEM will be applied to Inada granite as an example of hard crystalline volcanic rock and comparison of MFEM results with conventional methods will also be carried out.

\section{REFERENCES}

Alam, A.K.M.B, Niioka, M., Fujii, Y., Fukuda, D., \& Kodama J. 2014. Effects of confining pressure on the permeability of three rock types under compression International Journal of Rock Mechanics and Mining Sciences (In press)

Bear, J. 1972. Dynamics of fluids in Porous Media. New York: American Elsevier Publishing Company.

Biot, M.A., \& Wills, D.G., (1957). The elastic coefficients of the theory of consolidation. ASME Journal of Applied Mechanics, 24:594-601.

Dhakal, G., Yoneda, T., Kato, M., \& Kaneko, K. 2002. Slake durability and mineralogical properties of some pyroclastic and sedimentary rocks. Eng geol; 65:31-45.

Doi, S. (1963). Petrological and petrochemical studies of welded tuff. Reports of the geological survey of hokkaido; 29:30-103.

Fjaer, E., Holt R.M. \& Horsrud, P. 2008. Petroleum Related Rock Mechanics. 2nd ed. Amsterdam, Boston: Elsevier, 66-70.

Franquet, J. A. \& Abass, H. H. (1999). Experimental evaluation of Biot's poroelastic parameter - Three different methods, in 37th U.S. Symposium on Rock Mechanics (USRMS), June 7-9 Vail, CO, Balkema, Rotterdam, 349-355.

Ghabezloo, S., Sulem, J., Guédon, S. \& Martineau F. 2008. Effective stress law for the permeability of a limestone. International Journal of Rock Mechanics and Mining Sciences 46(4):761-768.

Terzaghi, K. 1936. The shearing resistance of saturated soils and the angle between the planes of shear, First Int. Conf. Soil Mech., Vol. 1, Harvard Univ., Cambridge, Mass.: 54-56.

Youn, H., \& Tonon, F. 2010. Multi-stage triaxial test on brittle rock. International Journal of Rock Mechanics \& Mining Sciences 47:678-684

Zaman, M., Roegiers, J.-C. Abdulraheem, A. \& Azeemuddin, M. 1994. Pore collapse in weakly cemented and porous rocks. J of Energy Resources Tech 116:97-103. 